\title{
The Association Between Ventilatory Ratio and Mortality in Children and Young Adults
}

\author{
Anoopindar K Bhalla, Junzi Dong, Margaret J Klein, Robinder G Khemani, and \\ Christopher JL Newth
}

\begin{abstract}
BACKGROUND: The ventilatory ratio (VR) is a dead-space marker associated with mortality in mechanically ventilated adults with ARDS. The end-tidal alveolar dead space fraction (AVDSf) has been associated with mortality in children. However, AVDSf requires capnography measurements, whereas VR does not. We sought to examine the prognostic value of VR, in comparison to AVDSf, in children and young adults with acute hypoxemic respiratory failure. METHODS: We conducted a retrospective study of prospectively collected data from 180 mechanically ventilated children and young adults with acute hypoxemic respiratory failure. VR was calculated as (minute ventilation $\left.\times \mathrm{P}_{\mathrm{aCO}_{2}}\right) /($ age-adjusted predicted minute ventilation $\times 37.5)$. AVDSf was calculated as $\left(\mathbf{P}_{\mathrm{aCO}_{2}}-\mathbf{P}_{\mathrm{ETCO}_{2}}\right) / \mathbf{P}_{\mathrm{aCO}_{2}}$. RESULTS: VR and AVDSf had a moderate correlation (rho 0.31, $P<.001$ ). VR was similar between survivors at 1.22 (interquartile range [IQR] 1.0-1.52) and nonsurvivors at $1.30($ IQR $0.96-1.95)(P=.2)$. AVDSf was lower in survivors at $0.12($ IQR $0.03-0.23)$ than nonsurvivors at $0.24(\mathrm{IQR} 0.13-0.33)(P<.001)$. In logistic regression and competing risk regression analyses, VR was not associated with mortality or rate of extubation at any given time (competing risk death; all $P>.3$ ). An AVDSf in the highest 2 quartiles, in comparison to the lowest quartile (AVDSf < 0.06), was associated with higher mortality after adjustment for oxygenation index and severity of illness (AVDSf $\geq 0.15-0.26$ : odds ratio $3.58,95 \%$ CI $1.02-12.64, P=.047$, and AVDSf $\geq 0.26$ : odds ratio $3.9195 \% \mathrm{CI}-1.03-14.83, P=.045)$. At any given time after intubation, a child with an AVDSf $\geq 0.26$ was less likely to be extubated than a child with an AVDSf $<\mathbf{0 . 0 6}$, after adjustment for oxygenation index and severity of illness (AVDSf $\geq 0.26$ : subdistribution hazard ratio $0.55,95 \%$ CI $0.33-0.94, P=.03$ ). CONCLUSIONS: VR should not be used for prognostic purposes in children and young adults. AVDSf added prognostic information to the severity of oxygenation defect and overall severity of illness in children and young adults, consistent with previous research. Key words: ARDS; pediatrics; mortality; prognosis; mechanical ventilators. [Respir Care 2021;66(2):205-212. (C) 2021 Daedalus Enterprises]
\end{abstract}

\section{Introduction}

Physiologic dead space represents areas of the respiratory system that receive ventilation without perfusion and is composed of both anatomic dead space and alveolar dead space. Alveolar dead space can be elevated for numerous

Ms Klein and Drs Bhalla, Khemani, and Newth are affiliated with the Department of Anesthesiology and Critical Care Medicine, Children's Hospital Los Angeles, Los Angeles, California. Drs Bhalla, Khemani, and Newth are affiliated with the Department of Pediatrics, Keck School of Medicine, University of Southern California, Los Angeles, California. Dr Dong is affiliated with the Philips Research North America, Acute Care Solutions Department, Cambridge, Massachusetts. reasons in critically ill children, including alveolar overdistention and pulmonary hypoperfusion. Markers of physiologic and alveolar dead space have been consistently associated with mortality in mechanically ventilated children and adults with ARDS. ${ }^{1-5}$

Markers of dead space were considered for defining ARDS severity in both the Berlin definition of ARDS as

\footnotetext{
Dr Newth presented a version of this paper at the American Thoracic Society 2019 International Conference, held May 17-22, 2019, in Dallas, Texas.

Supplementary material related to this paper is available at http://www. rcjournal.com.
} 


\section{Ventilatory Ratio and Pediatric Mortality}

well as the Pediatric Acute Lung Injury Consensus Conference pediatric ARDS definition. ${ }^{6,7}$ They were not included in either definition, partly due to the lack of routinely available established metrics to monitor dead space at the bedside. The most accepted estimate of physiologic dead space uses mean expired $\mathrm{P}_{\mathrm{CO}_{2}}\left(\mathrm{P}_{\overline{\mathrm{E}} \mathrm{CO}_{2}}\right)$ in the Bohr-Enghoff equation, where the ratio of dead space to tidal volume $\left(\mathrm{V}_{\mathrm{D}} / \mathrm{V}_{\mathrm{T}}\right)=$ $\left.\left(\mathrm{P}_{\mathrm{aCO}_{2}}-\mathrm{P}_{\overline{\mathrm{E} C O}}\right) / \mathrm{P}_{\mathrm{aCO}_{2}}\right){ }^{8} \mathrm{P}_{\overline{\mathrm{E} C O}}$ is most easily measured with volumetric capnograpy; however, volumetric capnography is rarely used in routine clinical practice.

We have previously reported that the end-tidal alveolar dead space fraction (AVDSf), calculated as $\left(\mathrm{P}_{\mathrm{aCO}_{2}}-\mathrm{P}_{\mathrm{ETCO}_{2}}\right) / \mathrm{P}_{\mathrm{aCO}_{2}}$, is a useful marker of alveolar dead space in children. ${ }^{9}$ The AVDSf relies on routinely available time-based capnography data and has prognostic significance in mechanically ventilated children., ${ }^{1,2}$ For adults with ARDS, Sinha et al recently suggested the ventilatory ratio (VR) as a marker of dead space that can be calculated using routinely available clinical data without any measures of capnography. ${ }^{10-12} \mathrm{VR}$ in adults is defined as:

$$
\begin{aligned}
\mathrm{VR}= & \left(\dot{\mathrm{V}}_{\mathrm{E}} \text { measured } \times \mathrm{P}_{\mathrm{aCO}_{2}} \text { measured }\right) / \\
& \left(\dot{\mathrm{V}}_{\mathrm{E}} \text { predicted } \times \mathrm{P}_{\mathrm{aCO}_{2}} \text { ideal }\right)
\end{aligned}
$$

where $\dot{\mathrm{V}}_{\mathrm{E}}$ measured is measured minute ventilation, $\dot{\mathrm{V}}_{\mathrm{E}}$ predicted is obtained by multiplying the predicted body weight by $100 \mathrm{~mL} / \mathrm{min} / \mathrm{kg}$, and $\mathrm{P}_{\mathrm{aCO}_{2}}$ ideal is set at 37.5 $\mathrm{mm} \mathrm{Hg}$.

Sinha et $\mathrm{al}^{13}$ reported that, in adults with ARDS, VR is correlated with $\mathrm{V}_{\mathrm{D}} / \mathrm{V}_{\mathrm{T}}$ and is independently associated with mortality. VR has not been studied in children with pediatric ARDS. The primary objective of this study was to investigate the association between a pediatric VR, adjusting for age-based differences in predicted $\dot{\mathrm{V}}_{\mathrm{E}}$, and mortality in children and young adults with acute hypoxemic respiratory failure (all met pediatric ARDS oxygenation criteria, although the requirement for a new infiltrate on chest radiograph was not specifically confirmed). We compared the performance of VR against AVDSf in the study cohort.

\section{Methods}

This was a retrospective analysis of prospectively collected data from children and young adults admitted to the pediatric ICU at Children's Hospital Los Angeles between January 2015 and December 2017. We identified all

The authors have disclosed no conflicts of interest.

Correspondence: Anoopindar K Bhalla MD MSCI, 4650 Sunset Blvd MS \#12, Los Angeles, CA 91214. E-mail: abhalla@chla.usc.edu.

DOI: $10.4187 /$ respcare.07937

\section{QUICK LOOK}

\section{Current knowledge}

Dead-space markers have been consistently associated with mortality in mechanically ventilated children and adults. The most well-accepted dead-space marker, calculated with the Bohr-Enghoff equation, requires measurement of mean expired $\mathrm{P}_{\mathrm{CO}_{2}}$ through monitoring devices that are generally not used in routine care. The ventilatory ratio is a dead-space marker that can be calculated from routinely available clinical data and is associated with mortality in mechanically ventilated adults with ARDS.

\section{What this paper contributes to our knowledge}

Ventilatory ratio was not associated with mortality and should not be used for prognostic purposes in mechanically ventilated children and young adults. The endtidal alveolar dead space fraction, which uses routinely available time-based capnography measurements and is associated with mortality in mechanically ventilated children and young adults, is preferred for prognostic purposes.

invasively mechanically ventilated patients $<21$ y old who met pediatric ARDS oxygenation criteria (ie, oxygenation index $[\mathrm{OI}]>4$ ) or oxygen saturation index $>5$ ) and had either arterial or capillary blood gases available for review. ${ }^{6}$ Subjects were included in this study if they had 2 OI or oxygen saturation index measurements, separated by $4 \mathrm{~h}$, that both met oxygenation criteria. Patients were excluded if they had respiratory failure related to cardiac disease, an endotracheal tube leak $>20 \%$, missing height data (ie, unable to estimate predicted body weight), or weight $<10$ $\mathrm{kg}$, and were on an AVEA ventilator (CareFusion, Yorba Linda, California) (ie, no automatic compensation for circuit compliance in volume calculations for the infant circuit). The study was approved by the Children's Hospital Los Angeles Institutional Review Board (CCI-09-00126, CCI-09-00287).

\section{Data Extraction and Procedures}

We used 3 data sources for this study: continuous data from the bedside patient monitors (Philips Healthcare, Andover, Massachusetts), a copy of the electronic health record (Cerner, Kansas City, Missouri), and an administrative database, which updated with diagnostic and demographic information by clinicians providing direct patient care (Microsoft, Redmond, Washington). These databases are routinely monitored for accuracy through random sampling of records. 
The timing of blood gases was determined by the clinical team. It is routine practice in our pediatric ICU to obtain blood gases during times of stability and not when ventilator changes or interventions have recently been performed (eg, endotracheal tube suctioning). Our pediatric ICU routinely monitors $\mathrm{P}_{\mathrm{ETCO}_{2}}$ with time-based capnography in all mechanically ventilated patients. Per unit policy, the $\mathrm{P}_{\mathrm{ETCO}_{2}}$ module is calibrated using 2 points at setup and every $12 \mathrm{~h}$ thereafter. A pressure-targeted mode of ventilation is routine in our pediatric ICU. PEEP was selected at the discretion of the clinical team.

Data from the first available blood gas were paired with ventilator and capnography data from the bedside monitor. Data were extracted in 30-s increments before and after the time of the blood gas. The mean value from the closest 4 data points to the blood gas for $\dot{\mathrm{V}}_{\mathrm{E}}, \mathrm{P}_{\mathrm{ETCO}_{2}}$, PEEP, peak inspiratory pressure, $\mathrm{S}_{\mathrm{pO}_{2}}, \mathrm{~F}_{\mathrm{IO}_{2}}$, and mean airway pressure were used in the analysis. We extracted data on demographics, diagnosis, 12-h Pediatric Risk of Mortality III (PRISM III) score, time to successful extubation (defined as remaining extubated for $>24 \mathrm{~h}$ ), and mortality. ${ }^{14}$

\section{Variable Definition}

Because the predicted $\dot{\mathrm{V}}_{\mathrm{E}}$ used in adults $(100 \mathrm{~mL} / \mathrm{kg} / \mathrm{min} \times$ predicted body weight) does not apply over the age range of children and young adults, a pediatric $\dot{V}_{\mathrm{E}}$ predicted was estimated. ${ }^{15,16}$ Pediatric predicted $\dot{\mathrm{V}}_{\mathrm{E}}(\mathrm{mL} / \mathrm{min})$ was estimated using the 50th-percentile age-based norm for breathing frequency, estimating $7 \mathrm{~mL} / \mathrm{kg}$ for $\mathrm{V}_{\mathrm{T}}$ and multiplying by predicted body weight (see the supplementary materials at http://www.rcjournal.com). ${ }^{17}$ In secondary analyses, we used (1) the 10th-percentile age-based norm for breathing frequency and an estimated $\mathrm{V}_{\mathrm{T}}$ of $6 \mathrm{~mL} / \mathrm{kg}$; (2) the 90th-percentile age-based norm for breathing frequency and an estimated $\mathrm{V}_{\mathrm{T}}$ of $8 \mathrm{~mL} / \mathrm{kg}$; and (3) a previously published pediatric predicted $\mathrm{V}_{\mathrm{T}}$ (ie, $4.19 \times$ height $(\mathrm{cm})-206.6)$ and the 50th-percentile age-based norm for breathing frequency to assess alternative methods of estimating pediatric $\dot{\mathrm{V}}_{\mathrm{E}}$ predicted for use in VR calculation. ${ }^{18}$ In 8 children, all under the age of 6 months, when the pediatric predicted $V_{T}$ equation yielded a $V_{T}<10$ $\mathrm{mL}$, a value of $10 \mathrm{~mL}$ was imputed for the analysis.

AVDSf is defined as $\left(\mathrm{P}_{\mathrm{aCO}}-\mathrm{P}_{\mathrm{ETCO}}\right) / \mathrm{P}_{\mathrm{aCO}}$. Capillary $\mathrm{P}_{\mathrm{CO}_{2}}$ was used when arterial $\mathrm{P}_{\mathrm{CO}_{2}}$ was not available. When a capillary blood gas was used, an oxygen saturation index was calculated (if $\mathrm{S}_{\mathrm{pO}_{2}} \leq 97 \%$ ) and converted to an OI equivalent as previously described. ${ }^{19}$ Predicted body weight was calculated using World Health Organization growth curves for infants and children $<2$ y old and from Centers for Disease Control grids for those 2-20 y old. $\Delta$ Pressure was defined as the difference between peak inspiratory pressure and PEEP. Driving pressure (ie, the difference between plateau pressure and PEEP) was not available because it is not common in our clinical practice to obtain inspiratory holds to measure plateau pressure during pressure-regulated modes. Subjects whose cause of death was primarily related to neurologic disease were identified to determine if the performance of VR improved in the subgroup with non-neurologic death.

\section{Outcomes}

Our primary outcome was pediatric ICU mortality. Rate of extubation at any given time after intubation was a secondary outcome.

\section{Statistical Analysis}

The correlation between AVDSf and VR was assessed with a Spearman correlation coefficient. We divided VR into quartiles and compared AVDSf across quartiles with a Kruskal-Wallis test. Pairwise comparisons were made with the Bonferroni correction.

Logistic regression was used to assess relationships between mortality and each dead-space marker. VR and AVDSf were modeled as categorical variables (quartiles) to meet model assumptions. Variables were considered for multivariable modeling if they had a univariable association $(P<.2)$ with mortality or if there was substantial existing published evidence for inclusion (PRISM III, OI). Variables that changed the dead-space parameter estimate by $>15 \%$ were considered confounders. Interaction terms were considered. Area under the curve was calculated to describe model discrimination. Model fit was assessed with a Hosmer-Lemeshow test. A $P$ value $<.05$ was considered significant. Analysis was performed using Stata 15 (StataCorp, College Station, Texas).

In secondary analyses, we used VR calculated using the 3 alternative methods of estimating a predicted pediatric $\dot{\mathrm{V}}_{\mathrm{E}}$ to determine if the association between VR and mortality was influenced by the assumptions we used in the primary analysis. We performed 3 sensitivity analyses: (1) limiting the analysis to non-neurologic deaths; (2) limiting the analysis to dead-space markers that were calculated with arterial $\mathrm{P}_{\mathrm{CO}_{2}}$; and (3) stratifying by the median age of $7 \mathrm{y}$ (age categories: $\leq 7 \mathrm{y}$ and $>7 \mathrm{y}$ ). ${ }^{20}$

\section{Competing Risk Regression Analysis}

For investigation of the secondary outcome of rate of extubation at any given time after intubation, we used a proportional hazards model for competing risks (ie, extubation was the primary outcome with the competing risk of death). This type of analysis allows for consideration of rate of extubation at any given time after intubation without noninformative censoring of subjects who die. Competing risk regression analyses, used to assess the duration of 
Table 1. Baseline Demographics and Clinical Characteristics by Survival

\begin{tabular}{|c|c|c|c|c|}
\hline Variables & $\begin{array}{l}\text { Total Sample } \\
\quad(N=180)\end{array}$ & $\begin{array}{l}\text { Survivors } \\
(n=133)\end{array}$ & $\begin{array}{l}\text { Nonsurvivors } \\
\quad(n=47)\end{array}$ & $P$ \\
\hline Age, months & $86.2(15.5-160)$ & $71(13-146)$ & $101(18-187)$ & .19 \\
\hline Male & $97(53.9)$ & $68(51.1)$ & $29(61.7)$ & .21 \\
\hline Predicted weight, $\mathrm{kg}$ & $21.4(8.6-38.9)$ & $20.3(8.5-38)$ & $27.3(8.6-44.2)$ & .20 \\
\hline \multicolumn{4}{|l|}{ Diagnosis } & .034 \\
\hline Aspiration & $5(2.8)$ & $3(2.3)$ & $2(4.3)$ & \\
\hline Cardiac arrest & $12(6.7)$ & $6(4.5)$ & $6(12.8)$ & \\
\hline Drowning & $3(1.7)$ & $1(0.8)$ & $2(4.3)$ & \\
\hline Pneumonia & $63(35)$ & $52(39)$ & $11(23.4)$ & \\
\hline Sepsis & 57 (31.7) & $38(28.6)$ & $19(40.4)$ & \\
\hline Trauma & $9(5)$ & $6(4.5)$ & $3(6.4)$ & \\
\hline Other & $31(17.2)$ & $27(20.3)$ & $4(8.5)$ & \\
\hline Oxygenation index & $9.5(5.6-15.7)$ & $8.6(5.4-13.8)$ & $12(6.4-23.3)$ & .01 \\
\hline PEEP & $9(7-12)$ & $8(6-11)$ & $10(8-13)$ & .032 \\
\hline$\Delta$ Pressure & $18(14-22)$ & $18(14-22)$ & $18(15-22)$ & .46 \\
\hline Minute ventilation, $\mathrm{mL} / \mathrm{kg} / \mathrm{min}$ & $172(130-228)$ & $173(128-226)$ & $170(134-236)$ & $>.99$ \\
\hline $\mathrm{P}_{\mathrm{aCO}_{2}}$ & $44(38-51)$ & $43(37-52)$ & $44(40-51)$ & .41 \\
\hline PRISM III raw score & $9(4-15)$ & $8(3-12)$ & $14(8-24)$ & $<.001$ \\
\hline AVDSf & $0.15(0.05-0.26)$ & $0.12(0.03-0.23)$ & $0.24(0.13-0.33)$ & $<.001$ \\
\hline Ventilatory ratio & $1.25(1.0-1.6)$ & $1.22(1.0-1.52)$ & $1.3(0.96-1.95)$ & .20 \\
\hline \multicolumn{5}{|c|}{$\begin{array}{l}\text { Continuous variables are presented as median (interquartile range) and were compared with a Mann Whitney } U \text { test. Categorical variables are presented as } n(\%) \text { and were compared with a chi-square test. } \\
\Delta \text { Pressure }=\text { positive inspiratory pressure }- \text { PEEP } \\
\text { PRISM III }=\text { Pediatric Risk of Mortality } \\
\text { AVDSf }=\text { end-tidal alveolar dead space fraction }\end{array}$} \\
\hline
\end{tabular}

mechanical ventilation with consideration of subjects who die, are being used more frequently in critical care research due to analytic advantages over the use of ventilator-free days. $^{21}$ We used the Fine and Gray method, which generates a subdistribution hazard ratio to estimate the rate of extubation at any given time after intubation while considering the competing risk of death. ${ }^{22}$ We tested the proportional hazard assumption using time-dependent covariates in the models.

\section{Results}

There were 200 children and young adults who met inclusion criteria; 20 of these were excluded, leaving 180 children and young adults in the study cohort. There were 97 males $(53.9 \%)$, and the median age was 86.2 months (interquartile range [IQR] 15.5-160) (Table 1). Mortality was $26.1 \%$, and duration of mechanical ventilation in survivors was $8.2 \mathrm{~d}$ (IQR 4.8-13.7). There were 15 (31.9\%) deaths that were related primarily to neurologic disease. Median AVDSf was 0.15 (IQR 0.05-0.26), and median VR was 1.25 (IQR 1.0-1.6).

VR and AVDSf had a moderate correlation (rho 0.31, $P<.001)$. When quartiles of VR were examined, AVDSf was significantly different across quartiles $(P<$.001) (Fig. 1). AVDSf was significantly lower in the first $3 \mathrm{VR}$

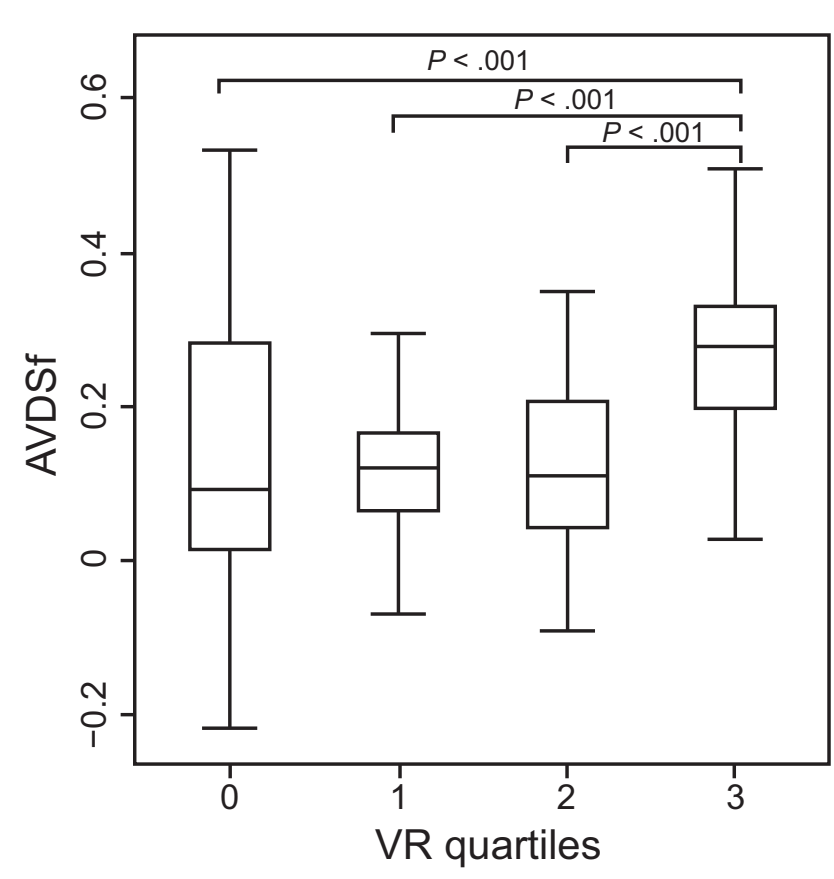

Fig. 1. End-tidal alveolar dead space fraction (AVDSf) by ventilatory ratio (VR) quartiles $(\mathrm{Q} 1<1$; Q2: $\geq 1-1.25$; Q3 > 1.25-1.63; Q4 > 1.63). $P$ values were determined with a Kruskal-Wallis test. The boxes represent the interquartile ranges with the median values represented by a bold line. Whiskers represent upper adjacent and lower adjacent values. Outliers are not shown. 
quartiles than in the highest VR quartile (Q1: AVDSf 0.09, IQR 0.01-0.28; Q2: AVDSf 0.12, IQR 0.06-0.17; Q3: AVDSf 0.11, IQR 0.04-0.21; vs Q4: AVDSf 0.28, IQR 0.2-0.33; all $P<.001$ ).

Median VR was similar between survivors and nonsurvivors (1.22, IQR 1.0-1.52, vs 1.30, IQR 0.96-1.95, $P=.20$ ) (Table 1). VR was not associated with mortality in logistic regression modeling (Table 2). Nonsurvivors had a significantly higher median AVDSf than survivors (0.24, IQR $0.13-0.33$, vs 0.12 , IQR $0.03-0.23, P<.001$ ). In multivariable logistic regression modeling, an AVDSf in the highest 2 quartiles, in comparison to the lowest quartile (AVDSf $<$ 0.06 ), was associated with mortality after adjustment for OI and PRISM III: AVDSf $\geq 0.15-0.26$ : odds ratio 3.58 (95\% CI 1.02-12.64), $P=.047$; and AVDSf $\geq 0.26$ : odds ratio 3.91 (95\% CI 1.03-14.83), $P=.045$ ) (Table 2).

In the secondary analyses, VR was not associated with mortality when using any of the 3 alternative methods of calculating the predicted pediatric $\dot{\mathrm{V}}_{\mathrm{E}}$ (see the supplementary materials at http://www.rcjournal.com).

\section{Sensitivity Analyses}

The first sensitivity analysis excluded death primarily related to neurologic causes (15 deaths excluded). The results were similar, and VR was not associated with mortality. The second sensitivity analysis restricted dead-space measurements (AVDSf or VR) to those that were calculated with an arterial $\mathrm{P}_{\mathrm{CO}_{2}}$ (eliminating 40 capillary $\mathrm{P}_{\mathrm{CO}_{2}}$ measurements). The results were similar, and VR was not associated with mortality. The third sensitivity analysis, stratifying by median age, revealed no association between VR and mortality in either age group (see the supplementary materials at http://www.rcjournal.com).

\section{Rate of Extubation}

In the secondary analyses, using a competing risk regression analysis, subjects in the lowest VR quartile had a similar rate of extubation at any given time after intubation to subjects in the higher 3 quartiles (all $P>.30$ ) (Table 3 ). At any given time after intubation, a child with an AVDSF $\geq .26$ was less likely to be extubated than a child with an AVDSF <0.06, after adjustment for OI and PRISM III (AVDSf $\geq .26$ : subdistribution hazard ratio 0.55 (95\% CI $0.33-0.94), P=.03)$.

\section{Discussion}

Our results indicate that VR is not associated with mortality or rate of extubation at any given time after intubation in children and young adults with acute hypoxemic respiratory failure. This is in contrast to the recent study by Sinha et $\mathrm{al}^{13}$ in adults with ARDS, who reported that VR was
Table 2. Logistic Regression Analyses for Association Between Dead Space Markers and Mortality

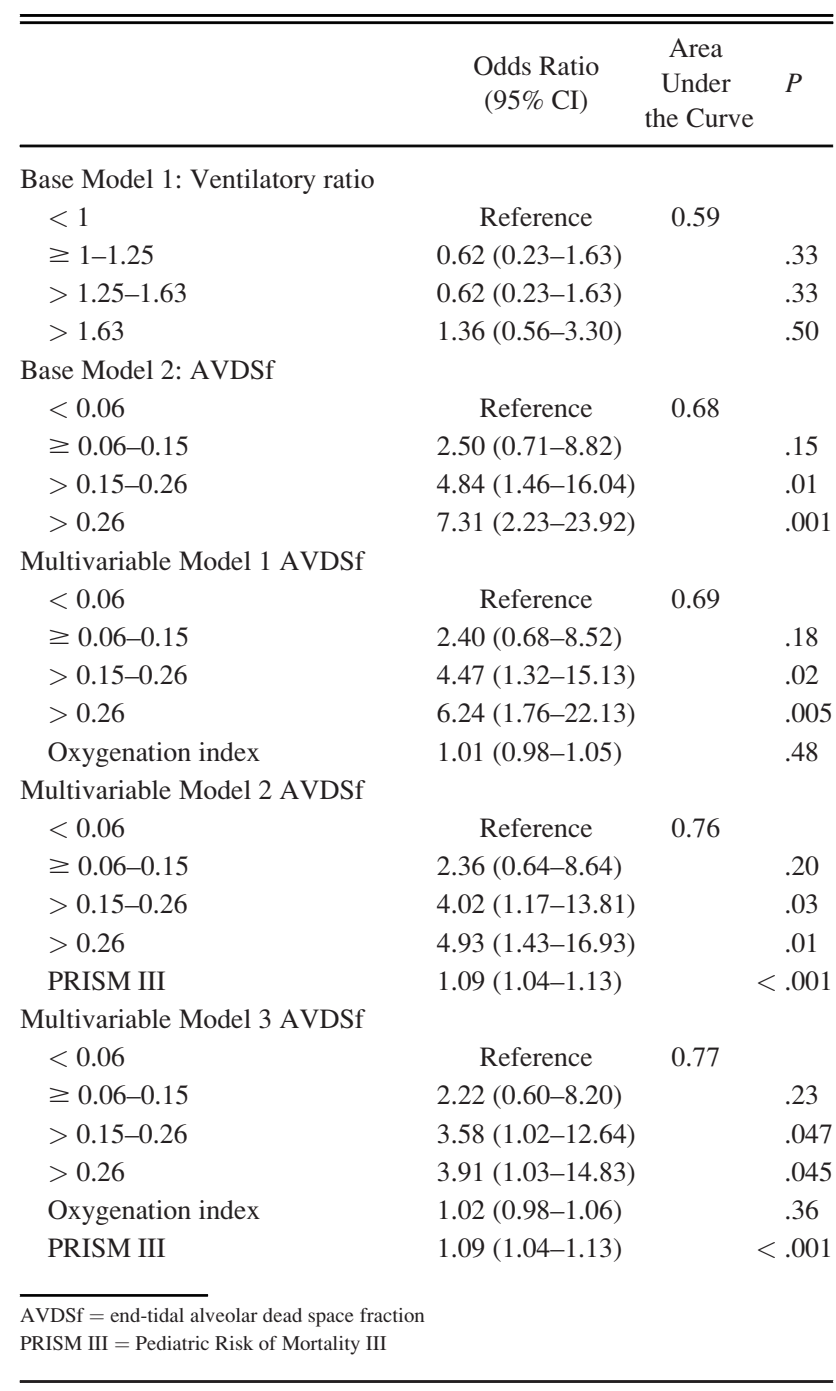

independently associated with mortality after adjusting for $\mathrm{P}_{\mathrm{aO}} / \mathrm{F}_{\mathrm{IO}_{2}}$, PEEP, and severity of illness. We confirmed, consistent with our previous research, that AVDSf adds prognostic value to oxygenation markers and severity of illness in children and young adults with acute hypoxemic respiratory failure. ${ }^{1,2}$

One of the reasons why VR does not perform as well as AVDSf for mortality discrimination in children and young adults with acute hypoxemic respiratory failure is due to the difficulty in estimating predicted $\dot{\mathrm{V}}_{\mathrm{E}}$ in children. In the adult VR equation, predicted $\dot{\mathrm{V}}_{\mathrm{E}}$ is based on $100 \mathrm{~mL} / \mathrm{kg} / \mathrm{min}$ and is normalized to predicted body weight. Children have differences in anatomic dead space and physiologic differences in oxygen consumption that change with age. ${ }^{15,16}$ These affect predicted $\dot{V}_{\mathrm{E}}$, making any estimated predicted $\dot{\mathrm{V}}_{\mathrm{E}}$ value invalid across the entire pediatric age spectrum. 
Table 3. Competing Risk Regression Analyses for Association Between Dead Space Markers and Rate of Extubation at Any Time After Intubation

\begin{tabular}{|c|c|c|}
\hline & $\begin{array}{c}\text { Subdistribution Hazard } \\
\text { Ratio }(95 \% \mathrm{CI})\end{array}$ & $P$ \\
\hline \multicolumn{3}{|c|}{ Base Model 1: Ventilatory ratio } \\
\hline$<1$ & Reference & \\
\hline$\geq 1-1.25$ & $1.22(0.74-2.02)$ & .43 \\
\hline$>1.25-1.63$ & $1.06(0.66-1.70)$ & .82 \\
\hline$>1.63$ & $0.78(0.46-1.31)$ & .34 \\
\hline \multicolumn{3}{|l|}{ Base Model 2: AVDSf } \\
\hline$<0.06$ & Reference & \\
\hline$\geq 0.06-0.15$ & $0.70(0.45-1.09)$ & .11 \\
\hline$>0.15-0.26$ & $0.51(0.32-0.83)$ & .006 \\
\hline$>0.26$ & $0.38(0.24-0.63)$ & $<.001$ \\
\hline \multicolumn{3}{|c|}{ Multivariable Model 1 AVDSf } \\
\hline$<0.06$ & Reference & \\
\hline$\geq 0.06-0.15$ & $0.73(0.47-1.13)$ & .16 \\
\hline$>0.15-0.26$ & $0.55(0.34-0.89)$ & .01 \\
\hline$>0.26$ & $0.43(0.26-0.72)$ & .001 \\
\hline Oxygenation index & $0.99(0.97-1.01)$ & .30 \\
\hline \multicolumn{3}{|c|}{ Multivariable Model 2 AVDSf } \\
\hline$<0.06$ & Reference & \\
\hline$\geq 0.06-0.15$ & $0.76(0.49-1.16)$ & .20 \\
\hline$>0.15-0.26$ & $0.57(0.35-0.93)$ & .03 \\
\hline$>0.26$ & $0.48(0.29-0.78)$ & .003 \\
\hline PRISM III & $0.96(0.94-0.98)$ & $<.001$ \\
\hline \multicolumn{3}{|c|}{ Multivariable Model 3 AVDSf } \\
\hline$<0.06$ & Reference & \\
\hline$\geq 0.06-0.15$ & $0.79(0.51-1.21)$ & .27 \\
\hline$>0.15-0.26$ & $0.62(0.38-1.02)$ & .057 \\
\hline$>0.26$ & $0.55(0.33-0.94)$ & .03 \\
\hline Oxygenation index & $0.99(0.97-1.01)$ & .20 \\
\hline PRISM III & $0.96(0.94-0.98)$ & $<.001$ \\
\hline \multicolumn{3}{|c|}{$\begin{array}{l}\text { A subdistribution hazard ratio }<1 \text { means a lower rate of extubation at any given time after intu- } \\
\text { bation. } \\
\text { AVDSf = end-tidal alveolar dead space fraction } \\
\text { PRISM III = Pediatric Risk of Mortality III }\end{array}$} \\
\hline
\end{tabular}

Neonates can have a predicted $\dot{\mathrm{V}}_{\mathrm{E}}$ as high as 300 $\mathrm{mL} / \mathrm{kg} / \mathrm{min}^{23,24} \mathrm{We}$ attempted to address this by using a variety of methods to estimate age-adjusted predicted $\dot{\mathrm{V}}_{\mathrm{E}}$; however, all of these calculations were based on assumptions and estimates, and none of them yielded a VR that performed well across pediatric age ranges.

There are additional reasons why VR may not perform well in children. Infants and younger children have smaller $\mathrm{V}_{\mathrm{T}}$ that may not be measured accurately by the ventilator, leading to inaccuracy of measured $\dot{\mathrm{V}}_{\mathrm{E}} \cdot{ }^{25}$ The sensitivity analysis based on age groups, however, did not suggest that VR performed better in older children. In addition, the best method to predict body weight in children is controversial, with multiple proposed methods, all of which have limitations. ${ }^{26}$ It is often difficult to measure height accurately in recumbent children, particularly those with scoliosis or contractures, which are common comorbidities encountered in the pediatric critical care unit. ${ }^{27}$ Furthermore, while it is likely true in both obese adults and obese children that lung volume is best estimated from predicted body weight, children who have failure to thrive may in fact have smaller lung volumes than those estimated by predicted body weight. ${ }^{28}$ Additionally, the $\dot{\mathrm{V}}_{\mathrm{E}}$ requirement can be elevated for other reasons than dead space, such as increased $\mathrm{CO}_{2}$ production from hypermetabolic states, which are not adequately captured in the VR equation. It is possible that differences in the underlying cause of ARDS in children versus adults, commonly indirect lung injury in adults and direct lung injury in children, may contribute to VR performing better in adult ARDS.

Both AVDSf and VR are affected to some degree by intrapulmonary shunt. The Enghoff modification of the Bohr equation for physiologic dead space makes the assumption that arterial $\mathrm{P}_{\mathrm{CO}_{2}}$ is equal to alveolar $\mathrm{P}_{\mathrm{CO}_{2}}$. This same assumption is true for VR and AVDSf calculation. When significant intrapulmonary shunt occurs, the arterial $\mathrm{P}_{\mathrm{CO}_{2}}$ may be higher than alveolar $\mathrm{P}_{\mathrm{CO}_{2}}$. However, this would artificially raise both VR and AVDSf and is therefore unlikely to be the reason behind the discrepant performance between VR and AVDSf in children and young adults.

AVDSf remained independently associated with mortality after controlling for both OI and PRISM III. On the other hand, OI was no longer associated with mortality or rate of extubation at any given time after intubation after adjusting for AVDSf. From this analysis, AVDSf clearly adds prognostic information to oxygenation markers and PRISM III. Furthermore, in this analysis, AVDSf performed better than OI. This may be related to dead-space markers providing important information on adequacy of pulmonary perfusion and cardiac output that may not be captured by oxygenation metrics. Given that AVDSf is a simple measure that can be easily calculated in any intubated child monitored with time-based capnography and with an arterial or capillary blood gas, we believe it should be used as the primary marker for risk stratification in children because it balances ease of use with strong prognostic relevance.

AVDSf does require an invasive measure of $\mathrm{P}_{\mathrm{CO}_{2}}$. Pediatric critical care practice has moved away from frequent arterial blood gases in all but the sickest patients. ${ }^{29}$ We used capillary $\mathrm{P}_{\mathrm{CO}_{2}}$ to calculate AVDSf for some subjects in this study and found consistent results with the subgroup limited to arterial $\mathrm{P}_{\mathrm{CO}_{2}}$ measurements. Therefore, we believe either an arterial blood gas or capillary blood gas can be used to estimate AVDSf with reasonable accuracy. We did not evaluate AVDSf for those with venous gases, which are increasingly used in pediatric critical care. Future 


\section{Ventilatory Ratio and Pediatric Mortality}

investigations are needed to understand whether venous blood gases from a central line have any relevance in estimates of dead space in children. With the growing abundance of literature suggesting we are missing a key component of severity of lung disease when we focus only on oxygenation defect, alternative noninvasive methods for assessment of the ventilation defect must be considered. This may be through advanced analysis of the volumetric capnography curve as suggested by Fletcher et $\mathrm{al}^{30}$ and Tusman et al ${ }^{8,31}$ to obtain an estimate of alveolar $\mathrm{P}_{\mathrm{CO}_{2}}$, or through consideration of noninvasive estimates of arterial $\mathrm{P}_{\mathrm{CO}_{2}}$ such as transcutaneous $\mathrm{P}_{\mathrm{CO}_{2}}$ measurements. ${ }^{32}$

This study has some limitations. We did not have data from volumetric capnography to estimate physiologic dead space $\left(\mathrm{V}_{\mathrm{D}} / \mathrm{V}_{\mathrm{T}}\right)$ using the Bohr-Enghoff equation. Although the correlation of $V_{D} / V_{T}$ may have been stronger with VR, it would not have changed the association of VR with outcome. We also did not review chest imaging to verify that all subjects in the study met full pediatric ARDS criteria; therefore, it is possible that some subjects did not have pediatric ARDS. Finally, it is possible that VR performs better in a specific pediatric ARDS population.

\section{Conclusions}

VR should not be used for prognostic purposes in children and young adults. AVDSf is an easily measured dead space marker with prognostic significance (associated with mortality and risk of extubation at any given time after intubation) in children and young adults with acute hypoxemic respiratory failure.

\section{REFERENCES}

1. Ghuman AK, Newth CJ, Khemani RG. The association between the end tidal alveolar dead space fraction and mortality in pediatric acute hypoxemic respiratory failure. Pediatr Crit Care Med 2012;13(1):11-15.

2. Bhalla AK, Belani S, Leung D, Newth CJ, Khemani RG. Higher dead space is associated with increased mortality in critically ill children. Crit Care Med 2015;43(11):2439-2445.

3. Nuckton TJ, Alonso JA, Kallet RH, Daniel BM, Pittet JF, Eisner $\mathrm{MD}$, et al. Pulmonary dead-space fraction as a risk factor for death in the acute respiratory distress syndrome. N Engl J Med 2002;346 (17):1281-1286.

4. Raurich JM, Vilar M, Colomar A, Ibanez J, Ayestaran I, PerezBarcena J, et al. Prognostic value of the pulmonary dead-space fraction during the early and intermediate phases of acute respiratory distress syndrome. Respir Care 2010;55(3):282-287.

5. Kallet RH, Zhuo H, Liu KD, Calfee CS, Matthay MA, National Heart Lung and Blood Institute ARDS Network Investigators. The association between physiologic dead-space fraction and mortality in subjects with ARDS enrolled in a prospective multi-center clinical trial. Respir Care 2014;59(11):1611-1618.

6. Khemani RG, Smith LS, Zimmerman JJ, Erickson S, Pediatric Acute Lung Injury C. Pediatric acute respiratory distress syndrome: definition, incidence, and epidemiology: proceedings from the Pediatric
Acute Lung Injury Consensus Conference. Pediatr Crit Care Med 2015;16(5 Suppl 1):S23-S40.

7. Ranieri VM, Rubenfeld GD, Thompson BT, Ferguson ND, Caldwell E, Fan E, et al. Acute respiratory distress syndrome: the Berlin Definition. JAMA 2012;307(23):2526-2533.

8. Tusman G, Sipmann FS, Bohm SH. Rationale of dead space measurement by volumetric capnography. Anesth Analg 2012;114 (4):866-874 .

9. Bhalla AK, Rubin S, Newth CJ, Ross P, Morzov R, Soto-Campos G, et al. Monitoring dead space in mechanically ventilated children: volumetric capnography versus time-based capnography. Respir Care 2015;60(11):1548-1555.

10. Sinha P, Fauvel NJ, Singh P, Soni N. Analysis of ventilatory ratio as a novel method to monitor ventilatory adequacy at the bedside. Crit Care 2013;17(1):R34.

11. Sinha P, Fauvel NJ, Singh S, Soni N. Ventilatory ratio: a simple bedside measure of ventilation. Br J Anaesth 2009;102(5):692697.

12. Sinha P, Singh S, Hardman JG, Bersten AD, Soni N. Evaluation of the physiological properties of ventilatory ratio in a computational cardiopulmonary model and its clinical application in an acute respiratory distress syndrome population. Br J Anaesth 2014;112 (1):96-101.

13. Sinha P, Calfee CS, Beitler JR, Soni N, Ho K, Matthay MA, et al. Physiologic analysis and clinical performance of the ventilatory ratio in acute respiratory distress syndrome. Am J Respir Crit Care Med 2019;199(3):333-341.

14. Pollack MM, Patel KM, Ruttimann UE. PRISM III: an updated Pediatric Risk of Mortality score. Crit Care Med 1996;24 (5):743-752.

15. Numa AH, Newth CJ. Anatomic dead space in infants and children. J Appl Physiol 1996;80(5):1485-1489.

16. Smallwood CD, Walsh BK, Bechard LJ, Mehta NM. Carbon dioxide elimination and oxygen consumption in mechanically ventilated children. Respir Care 2015;60(5):718-723.

17. Fleming S, Thompson M, Stevens R, Heneghan C, Plüddemann A, Maconochie I, et al. Normal ranges of heart rate and respiratory rate in children from birth to 18 years of age: a systematic review of observational studies. Lancet 2011;377(9770):1011-1018.

18. Kerr AA. Dead space ventilation in normal children and children with obstructive airways diease. Thorax 1976;31(1):63-69.

19. Khemani RG, Thomas NJ, Venkatachalam V, Scimeme JP, Berutti T, Schneider JB, et al. Comparison of $\mathrm{SpO} 2$ to $\mathrm{PaO} 2$ based markers of lung disease severity for children with acute lung injury. Crit Care Med 2012;40(4):1309-1316.

20. Dowell JC, Parvathaneni K, Thomas NJ, Khemani RG, Yehya N. Epidemiology of cause of death in pediatric acute respiratory distress syndrome. Crit Care Med 2018;46(11):1811-1819.

21. Yehya N, Harhay MO, Curley MAQ, Schoenfeld DA, Reeder RW. Reappraisal of ventilator-free days in critical care research. Am J Respir Crit Care Med 2019;200(7):828-836.

22. Fine JP, Gray RJ. A proportional hazards model for the subdistribution of a competing risk. J Am Stat Assoc 1999;94(446):496-509.

23. Greenspan JS, Abbasi S, Bhutani VK. Sequential changes in pulmonary mechanics in the very low birth weight (less than or equal to 1000 grams) infant. J Pediatr 1988;113(4):732-737.

24. Stocks J, Dezateux CA, Jackson EA, Hoo AF, Costeloe KL, Wade AM. Analysis of tidal breathing parameters in infancy: how variable is TPTEF:TE? Am J Respir Crit Care Med 1994;150 (5 Pt 1):1347-1354.

25. Kim P, Salazar A, Ross PA, Newth CJ, Khemani RG. Comparison of tidal volumes at the endotracheal tube and at the ventilator. Pediatr Crit Care Med 2015;16(9):e324-331. 


\section{Ventilatory Ratio and Pediatric Mortality}

26. Ward SL, Quinn CM, Steurer MA, Liu KD, Flori HR, Matthay MA. Variability in pediatric ideal body weight calculation: implications for lung-protective mechanical ventilation strategies in pediatric acute respiratory distress syndrome. Pediatr Crit Care Med 2018;19(12):e643-e652.

27. Rasouli MA, Newth CJL, Khemani RG, Ross PA. Predicting body height in a pediatric intensive care unit using ulnar length. Front Pediatr 2018;6:187.

28. Kim GJ, Newth CJL, Khemani RG, Wong SL, Coates AL, Ross PA. Does size matter when calculating the "correct" tidal volume for pediatric mechanical ventilation?: A hypothesis based on FVC. Chest 2018;154(1):77-83.

29. Khemani RG, Rubin S, Belani S, Leung D, Erickson S, Smith LS, et al. Pulse oximetry vs. $\mathrm{PaO} 2$ metrics in mechanically ventilated children:
Berlin definition of ARDS and mortality risk. Intensive Care Med 2015;41(1):94-102.

30. Fletcher R, Jonson B, Cumming G, Brew J. The concept of deadspace with special reference to the single breath test for carbon dioxide. Br J Anaesth 1981;53(1):77-88.

31. Tusman G, Sipmann FS, Borges JB, Hedenstierna G, Bohm SH. Validation of Bohr dead space measured by volumetric capnography. Intensive Care Med 2011;37(5):870-874.

32. Bhalla AK, Khemani RG, Hotz JC, Morzov RP, Newth CJ. Accuracy of transcutaneous carbon dioxide levels in comparison to arterial carbon dioxide levels in critically ill children. Respir Care 2019;64 (2):201-208

This article is approved for Continuing Respiratory Care Education credit. For information and to obtain your CRCE

(free to AARC members) visit

www.rcjournal.com 